\title{
La experiencia del desamparo en novelas de João Gilberto Noll, Chico Buarque y Michel Laub ${ }^{1}$
}

The experience of abandonment in novels by João Gilberto Noll, Chico Buarque and Michel Laub

\author{
Natalia López Rico \\ Universidad de Bonn \\ nlopezrico@gmail.com \\ Matías Marambio \\ Universidad Alberto Hurtado \\ mmarambio@uahurtado.cl \\ Horst Nitschack \\ Universidad de Chile \\ hnitschack@u.uchile.cl
}

\section{Resumen}

El presente artículo desarrolla una lectura de textos literarios desde el campo delimitado por las teorizaciones sobre afectos. A partir del análisis de tres novelas brasileñas contemporáneas, Bandoleros (1985), de Joao Gilberto Noll; Estorvo (1991), de Chico Buarque y Longe da água (2004), de Michel Laub, se explora la dimensión política y performativa del desamparo como afecto. La lectura apunta a las posibilidades y limitaciones sociales del desamparo considerando dos ejes en los que se evidencian su apertura y su incertidumbre: la crisis y la descomposición de los vínculos sociales en Bandoleros y en Longe da água, y los quiebres de la comunicación y el lenguaje en Estorvo. En ambos, la violenta dinámica procesual del desamparo está marcada por la descomposición de las subjetividades de los protagonistas que alcanza un punto de ruptura, el cual puede prefigurar nuevas singularidades y formas de lo común.

Palabras clave: narrativa brasileña contemporánea, afectos, desamparo, Joao Gilberto Noll, Chico Buarque, Michel Laub.

1 Este artículo forma parte del Proyecto Fondecyt n ${ }^{\circ} 1180230$ "Urbanidad, subjetividad y afectos en la literatura brasileña contemporánea”. 


\begin{abstract}
This article presents a reading of literary texts from the perspective of theories of affect. An analysis of three contemporary Brazilian novels —Bandoleiros (1985) by Joao Gilberto Noll, Estorvo (1991) by Chico Buarque, and Longe da água (2004) by Michel Laub - provides the basis of an exploration of the political and performative dimensions of abandonment as an affect. The analysis focuses on the social opportunities and restrictiveness of abandonment in relation to two core themes that illustrate the initiation of the process and the uncertainty involved: crisis and the deterioration of social ties in Bandoleiros and Longe da água, and the breakdown of language and communication in Estorvo. In both cases, the violent procedural dynamic of abandonment is marked by the decomposition of the protagonists' subjectivities, a process which reaches breaking point and leads to a reconfiguration of singularities and the emergence of new forms of the ordinary.
\end{abstract}

Keywords: contemporary brazilian narrative, affects; abandonment, Joao Gilberto Noll, Chico Buarque, Michel Laub.

Recibido: 05/10/2020

Aceptado: 16/08/2021

\title{
Introducción
}

En este artículo se analizan tres obras de la narrativa brasileña contemporánea a partir de las consideraciones abiertas por el giro afectivo: Bandoleros (1985), de Joao Gilberto Noll; Estorvo (1991), de Chico Buarque y Longe da água (2004), de Michel Laub. ${ }^{2}$ Se trata de tres autores destacados de la renovación narrativa de la literatura brasileña desplegada en torno al final de la dictadura militar (1985), una renovación que, tal como sostiene nuestra lectura, estuvo marcada por la crisis del sujeto y de la subjetividad y que observamos a partir de la teoría de afectos y su énfasis en las dinámicas producidas entre el sujeto y los afectos. En este contexto nos centraremos en las premisas teóricas que Vladimir Safatle abre en su libro El circuito de los afectos donde resitúa a los afectos como elementos políticos clave de transformación social, incluyendo la potencialidad de afectos hasta entonces desconsiderados ${ }^{3}$ o

2 El giro afectivo provocó en el ámbito de las humanidades un (re)descubrimiento de la potencialidad
de los afectos revelando su impacto en la vida política, en la regulación o desregulación de la vida social
así como su trabajo y presencia en la constitución de subjetividades. Véase Ana Abramowski y Santiago
Canevaro. "Introducción" en: Pensar los afectos, aproximaciones desde las ciencias sociales y las humanidades; el
prólogo de Helena López González de Orduña en La política cultural de las emociones de Sara Ahmed;
y "El giro afectivo" de Ali Lara y Giazú Enciso Domínguez.
3 El análisis de las dinámicas de los afectos llamados "tristes", o los ugly feelings según Ngai, también 
tomados como tristes (Spinoza), y criticando a su vez el posicionamiento de los "afectos" felices que tanto han servido como máscara para velar aquellos que permiten la sujeción (como el miedo) o crear y ambientar los paisajes extasiados y anestesiados del capitalismo (como la felicidad). ${ }^{4}$ Es a partir de esta tradición, con Freud a la cabeza, que Safatle arriesga una defensa del hasta entonces excluido desamparo (contra el miedo y la esperanza como afectos maestros de la Modernidad) como un afecto desde el cual reconstituir un circuito afectivo e instaurar una nueva comunidad política y ética que tendría como punto de partida un dejarse afectar total por el otro desde un suelo antipredicativo de sí mismo. Para el autor:

. . .el desamparo crea vínculos no solo a través de la transformación de toda apertura al otro en demandas de amparo, también crea vínculos por desposesión y por absorción de contingencias. Estar desamparado significa estar abierto a un afecto que me despoja de los predicados que me identifican $(23-4)$.

Una radical apertura hacia el/los otro/s pasaría así por la desposesión de los atributos que comúnmente nos definen y constituyen, una destitución identitaria que para desembocar en el desamparo debería antes atravesar una necesaria ruptura de las composiciones y estructuras tradicionales que han pensado y representado a los sujetos, en suma, un quiebre de circuitos afectivos tradicionales y de formas de representación de la subjetividad socialmente impuesta que, como intentaremos mostrar, sería posible observar en nuestras novelas (45).

Ahora, si bien las dinámicas afectivas a las cuales están expuestas las subjetividades de los protagonistas de las novelas parecen conducirlos a un desamparo radical, este afecto no prefigura una condición irrenunciable para su eventual recomposición emancipadora, un horizonte abierto por Safatle en su lectura del desamparo. De este modo, intentaremos demostrar cómo en las narraciones se revelan dimensiones del desamparo que perfilan otros circuitos afectivos donde los afectos habituales en los que se sedimenta la sumisión al sistema capitalista y liberal aparecen puestos en jaque (afectos vinculados al trabajo, a las instituciones,

está presente en los trabajos de J. Flatley y la melancolía, el optimismo cruel de L. Berlant, o el miedo en Massumi, entre otros.

4 Quizá la misma urgencia marca el lugar diferenciado que en este renovado punto de vista ocupa El circuito de los afectos, el cual prescinde de la discusión con los autores y autoras en boga (los autores más renombrados del reciente giro afectivo brillan por su ausencia, así como aquellos autores en quienes se apoyarían, especialmente Deleuze) y retoma una tradición filosófica y psicoanalítica que podríamos adjetivar de clásica. 
a la familia, etc.); es decir, revelan apenas el trabajo procesual de subjetividades en transformación marcadas por las violencias del desamparo.

Los protagonistas son figuras de la historia contemporánea cuyas vidas cotidianas se mueven entre Rio de Janeiro (Estorvo), São Paulo (Longe da água) y Porto Alegre (Bandoleros, Longe da água), además de un viaje a Estados Unidos realizado por el protagonista de Bandoleros. En contraste con la novela de formación tradicional, se observa que la socialización primaria y secundaria de los protagonistas es apenas cuestionada o problematizada en estas narraciones. Sus subjetividades más bien representan la normalidad social de nuestro tiempo, una normalidad marcada por contactos sociales casuales y vidas sin cohesión o participación social profunda o problemática. Solo cuando irrumpe el momento de la crisis - tema de las tres novelas - los personajes principales toman consciencia de la precariedad de su subjetividad y empiezan a experimentarla como farsa y artificio. O mejor, al revés: la subjetividad como resultado de instituciones sociales que han perdido su potencial de crear cohesiones sociales y de filtrar e interpretar la diversidad de afectos a los cuales cada individuo se expone, esta subjetividad se derrumba bajo las experiencias a las cuales los protagonistas son empujados por los afectos, exponiéndolos a un desamparo radical. ${ }^{5}$

Es en este punto donde la lectura de las tres novelas confirman una parte central de las reflexiones teóricas de Safatle: ${ }^{6}$ solo a partir del momento en el cual la subjetividad, y con ello, la identidad asumida — ambas como resultado de una economía afectiva organizada por las fuerzas hegemónicas-, se revela como altamente vulnerable, débil e insuficiente frente a los desafíos afectivos múltiples y colapsa, los protagonistas tendrían alguna oportunidad de reubicarse o de reorientarse en la vida, un horizonte que, no obstante, en las tres narraciones queda por completo

5 La subjetividad a la que hace referencia este artículo asume la crítica de cualquier subjetividad sea transcendental o idealista (del tipo de la subjetividad romántica fichtiana). Partimos de un concepto de subjetividad entendida como el resultado de procesos históricos y sociales, lo que nos lleva a la constatación de la posibilidad de subjetividades múltiples frente a las cuales el individuo tiene que responder, o ante cuyas exigencias se siente confrontado.

6 Estas tienen una deuda obvia, comprobada por las citas, con la Escuela de Frankfurt y en consecuencia varios puntos en común con el pensamiento de Benjamin: por ejemplo, el ‘suspenso' en la 'dialéctica en suspenso’ y la huelga general como ruptura con la continuidad de la historia y condición de la salvación; la 'mimesis a la muerte', la renuncia a cualquier predicación propia como condición de la sobrevivencia; el 'Estado de emergencia' radical (Ausnabmezustand) como condición de una renovación fundamental. Desde esta perspectiva, consideramos que la conceptualización del desamparo que propone Safatle está en una próximidad inmediata con las circunstancias que permiten la intervención de lo mesiánico: solamente el ser completamente desamparado está en condiciones de abrirse y de disponerse a recibir la revelacióno o la iluminación mesiánica. 
abierto. El punto más radical al cual exponen estas narraciones a sus protagonistas es a una inseguridad extrema que involucra una apertura completa hacia un futuro también abierto.

Las tres novelas guardan, de hecho, algunas similitudes con las tradicionales novelas de formación -más evidente, tanto en su estructura como en su contenido, en el caso de Longe da água - aunque con una gran diferencia: no se trata en ningún caso, como ya fue señalado, de experiencias de 'formación'; asistimos, por el contrario, a un proceso de deformación y de desaprendizaje de la subjetividad adquirida desde un deseo difuso de adquirir otra subjetividad que emerge de la singularidad radical, sin la perspectiva de una comunidad o sociedad alternativa que logre integrar esta singularización. En el mundo de contingencias que habitan los protagonistas de las novelas aquí analizadas, un mundo que depende de las casualidades y del azar y cuyas realidades son divergentes y contradictorias, no existe la posibilidad de la conciliación dialéctica de las contradicciones en una consciencia heroica, tal como ocurre en las novelas de formación. Sus múltiples vivencias apenas permiten que emerja una subjetividad problemática permanentemente puesta en desposesión.

Así, en la cohesión narrativa en ocasiones arbitraria de las tres novelas, la subjetividad del narrador aparece como efecto de las técnicas sociales a las cuales está sometido y como consecuencia de lazos familiares o de amistades con los cuales no se identifica o a los cuales se resiste. Estéticamente esto se evidencia en la construcción del narrador, un narrador en primera persona que relata su propia historia en un monólogo extenso y a veces incoherente, narradores sin nombre, sin fuerza para constituirse a sí mismos como sujetos, a pesar de que el propio narrador parece ser el único destinatario de este ajuste de cuentas. De ahí que los narradores no se dirijan al lector y aparentemente tampoco se preocupan por la coherencia de su narración, ni si esta es comprendida por un tercero. Las escrituras se presentan así como una herida, se abren ficciones dentro de las ficciones que dan un aura de irrealidad y de narradores descentrados, de sujetos que no están amparados por lógicas del cuidado ni tampoco las ejercen. ${ }^{7}$

Ahora bien, lo que colapsa en las tres novelas es la dinámica propia de economías afectivas que sustentan a la subjetividad: algo que brota de lo más individual de los protagonistas, de la singularidad de su 'intimidad', cuestiona de forma radical dicha economía. De hecho, esta vida íntima parece ofrecerse como instancia

7 Flora Sussekind da cuenta de la aparición, en la narrativa brasileña de fines de los ochenta y principios de los noventa, de narradores que deambulan a veces erráticamente por la ciudad y que en su tránsito ficcionalizan la experiencia urbana de los sin techo y las estrategias de sobrevivencia en la calle (65). 
preservadora de una sensibilidad ante las contradicciones y antinomias ocultas y reprimidas por los grandes relatos — a pesar de que la identificación con ellos promete la conciliación, aun si fuera problemática, con una subjetividad socialmente reconocida. O, más precisamente: lo que les afecta, pero no se integra o absorbe por una subjetividad 'oficial' o prescrita, es desplazado o reprimido hacia una instancia difusa y anómica en el aparato psíquico de los protagonistas, desde donde emergen las energías que hacen derrumbar su subjetividad.

Proponemos entonces interpretar la subjetividad —en el sentido de 'sujeción' (Butler) ${ }^{8}$ - como resultado de los circuitos de afectos y de la economía afectiva a la cual se encuentran sometidos los protagonistas narradores. Estos afectos son el resultado de totalidades económicas, sociales e institucionales cuya complejidad queda completamente oculta para los sujetos. "Sie wissen das nicht, aber sie tun es" ("No lo saben, pero lo hacen" (Marx 88)). No obstante, al mismo tiempo, en sus contactos sociales los protagonistas de estas novelas están expuestos a afectos que no se dejan subsumir bajo los esquemas de las subjetividades prescritas. Son afectaciones que provienen desde fuera, de experiencias que permanecen 'inexplicables' o son 'innombrables' dentro de los registros culturalmente aceptados (por ejemplo, en Longe da água, la muerte de Jaime) o afectaciones que actúan desde dentro, desde el propio cuerpo o desde el inconsciente (en Bandoleros y Estorvo los actos inexplicables e irracionales), es decir, desde la singularidad de su intimidad completamente desamparada en su confrontación con la subjetividad prescrita.

En suma, si la subjetividad oficial es el terreno que niega la experiencia del desamparo, asistimos en estas tres novelas a un escenario en el cual el desamparo radical retorna y es vivido y experimentado como descomposición de una subjetividad plegada a los esquemas oficiales. Ella no resiste a las pulsiones aún difusas que reclaman otra subjetividad que corresponde a la multiplicidad de afectaciones igualmente difusas que se manifiestan en un malestar general, en hastío (el spleen), en actos agresivos irracionales o autodestructivos. Así, la exploración de la dimensión política y performativa del desamparo como afecto, apuntando a sus posibilidades y limitaciones sociales, nos permite proyectar dos ejes que oscilan entre su apertura y su incertidumbre: la crisis y la descomposición de los vínculos sociales en Bandoleros y en Longe da água, y los quiebres de la comunicación y el lenguaje en Estorvo.

8 Según Butler, el sujeto se forma en el acto de sujeción. Con ello, la autora retoma un argumento de Foucault: "Deberíamos comprender el sometimiento en su manifestación material como constitución de los sujetos" (Foucault citado en Butler 11). 


\section{Bandoleros y la crisis del lazo social}

Bandoleros se caracteriza por la cohabitación de lo que se siente inconexo. El narrador-protagonista se desplaza entre Porto Alegre, Rio de Janeiro y Boston en un tiempo fragmentado, confuso y, curiosamente, desinteresado por el suspenso o el dramatismo. Solo hacia el final de la novela comprendemos la conexión entre las acciones narradas y sus señales anticipatorias, por eso la trama se presenta de forma cuidadosa para realzar la confusión fragmentaria de un mundo que carece de seguridad o sentido, un mundo en el cual el narrador cae en un desamparo radical.9 Incluso, tras intentar una organización lineal de la narración se hace obvio que la trama de Bandoleros se desenvuelve en un mundo signado por afectos que llevan al desamparo del protagonista, en la medida en que las construcciones habituales de la subjetividad se deshacen. La arbitrariedad narrativa se refleja en la ausencia de normas y reglas sean ellas sociales, morales o afectivas en el mundo del narrador. Es el mundo, como Durkheim lo llamaba, de la anomia. Salvo mínimas excepciones, sus personajes construyen conexiones frágiles en las cuales ni siquiera los lazos emocionales garantizan estabilidad.

En línea con lo que hemos planteado, proponemos leer el problema del lazo social en Bandoleros a partir de las lógicas de desamparo presentes en el texto, un universo donde las interacciones afectivas de los personajes no son la traducción de un estado de cosas interno hacia una exterioridad (el paso de lo subjetivo de la psicología a lo objetivo de las relaciones sociales). La pregunta por la desposesión y sus manifestaciones en el mundo de los personajes de la novela nos permitirá esclarecer el tipo de vínculo social que el texto figura estéticamente. Pero antes, vale la pena que volvamos a las premisas de Vladimir Safatle con respecto a la articulación entre el desamparo y la corporeidad social que cabría esperar de un circuito de afectos que nos expone a este afecto, un afecto que podría crear "vínculos por desposesión y por absorción de contingencias" (23-4). Creemos que esta intuición es clave para nuestra interpretación de Bandoleros, pues el conjunto de interacciones representadas por Noll en su novela está marcado por un desinterés —o más todavía, un rechazo - respecto de la empatía como principio de cohesión social. ${ }^{10}$ Antes que ofrecer una contención esperanzadora como resultado de su identifica-

9 Lo que distingue el desamparo de los protagonistas de estás novelas de la 'indigencia' o del 'desamparo transcendental' que Lukács diagnostica en la 'Teoría de la novela', es exactamente que este desamparo no es 'transcendental', si no, real: es síquico, social y económico.

10 La revisión crítica de la empatía como mecanismo que activa dinámicas conservadoras de la jerarquía social es una característica de algunos referentes de la teoría de afectos, como Ahmed, para quien "los discursos de compasión caritativos nos muestran de manera amplia que las historias de dolor involucran relaciones complejas de poder" (49). 
ción con las subjetividades convencionales, los personajes comparten una apertura a las manifestaciones de su precariedad emocional o a las pulsiones de sus deseos, incluso en lo que tienen de auto-destrucción, ${ }^{11}$ lo que corresponde a la disolución de su subjetividad. Ello es particularmente notorio en la trayectoria del narrador, que experimenta su desposesión como un desprendimiento y no como un trauma; se acerca más a la renuncia que a la expoliación. De este modo, la trama afectiva de la novela tiene como una de sus lógicas constructivas el desamparo como pivote del desmonte de la sociabilidad tradicional, alienada y alienante.

Un conjunto de episodios que incluyen al narrador y a Steve, personaje que conoce en Boston mientras hace tiempo para tomar un vuelo que lo llevará de vuelta a Brasil, sirven como ventana para esta problemática, pues se desenvuelven a partir de un encuentro azaroso con un extraño que luego deriva en una exploración de las distintas intensidades que puede adoptar el desamparo. La primera mención del personaje de Steve aparece al inicio de la novela, aunque solo logramos percibirla retrospectivamente, y ocurre bajo la forma de un llamado telefónico que el protagonista atiende sin comprender bien sus motivaciones o significado: "En el teléfono, una voz de hombre habla en inglés. Solo que el tipo o está borracho o está loco. No entiendo nada de lo que dice” (15).

Varias interferencias designan la dificultad para establecer un puente comunicativo entre el narrador y Steve, todas ellas referidas a un quiebre en el flujo del lenguaje: un idioma que no es el propio, la alteración narcótica de la conciencia y, por último, la inestabilidad psíquica. Aunque el protagonista logra aislar unidades de sentido - la proveniencia del interlocutor como función de su acento, la información de tiempo y lugar para un posible encuentro (“a la tarde estaré ahí”)—, su reacción insiste en su incapacidad para comprender el discurso del otro.

En propiedad, el primer encuentro con Steve ocurre durante la visita del protagonista a Boston, reseñado recientemente. Al entrar a un bar cerca de la casa donde vivía su esposa, Ada, inicia una interacción con un extraño en el local, acaso por descuido y arrepintiéndose casi inmediatamente: "No sé por qué le di ese margen de conversación. Eso me pasaba a veces: hacer exactamente lo contrario de lo que deseaba" (134). En la tierra-de-nadie de la espera de su viaje y cada vez más distanciado afectivamente de Ada, el protagonista se entrega a la deriva de este acercamiento inesperado a un completo desconocido, con la búsqueda tácita del choque y la violencia. En efecto, el pasaje es claro en mostrar que el protagonista

11 Freud también se refiere en Más allá del principio de placer (1920) a la pulsión de la autodestrucción, la 'pulsión de la muerte'. Es una pulsión de la descomposición que recuerda los afectos de descomposición de Spinoza. 
no desea esa intimidad con Steve, se arrepiente de haber cedido al impulso por involucrarse en una situación que no lo satisface. De hecho, la situación evidencia la discrepancia entre afectos y emociones tal como intentamos comprenderla: hay algo, para el propio narrador, que es innombrable, que lo afecta y lo moviliza contra sus propias emociones y sentimientos. Se produce una pulsión por ir hacia lo contrario del deseo que se alza como la razón, el fundamento de los contactos desamparados que se construyen en la novela, pues marca un camino que niega el alineamiento entre el deseo y las acciones que llevan a su realización, incluso si ello lleva a negar, también, un principio de autoconservación.

El contacto con Steve se inicia a partir de señas, lenguaje corporal cómplice de dos hombres que quieren emborracharse empujados por afectos a los cuales no corresponde ni un sentimiento de simpatía ni de amistad. En adelante, no obstante, estos afectos desamparados provocan una solidaridad del narrador con Steve que él mismo no logra entender. Una vez llegan a la casa de Steve en los suburbios de Boston y sin que se nos ofrezcan causas claras o lógicas, Steve entra en una escena maníaca en la que blande unas tijeras de cortar el pasto y entra, luego, en un colapso nervioso que lo deja en un virtual estado de coma: "Pero Steve me mira como si no me comprendiera. Sus ojos parecían realmente tan vacíos que no tenían cómo suponer nada. Si al menos le diera un fulminante motivo de odio... ¿ Ni siquiera venir contra mí con esa tijera de jardinería, ni siquiera eso?" (142). Las afectaciones que invaden a Steve ni siquiera se traducen en emociones, lo des-subjetivizan completamente. Lo reducen al puro cuerpo. El propio narrador comenta: "Pero el hecho es que Steve no me llevaría a nada más allá de la pura aflicción. Era un hombre que ya no sabía ser. Cortar pasto o defecar: lo mismo" (146).

¿Qué tipo de circuito de afectos se trama entre Steve y el protagonista en esta situación de vulnerabilidad, narrada en el tono seco y distanciado que predomina en toda la novela? ¿Puede leerse el episodio como la expresión de un cortocircuito de afectos, la interrupción del flujo que vincula y compone el lazo social? O bien, la creación de un equilibrio precario e inestable que apenas permite al protagonista percibir a Steve como "un hombre que ya no sabía ser". ${ }^{12}$ Lo que los conecta es, como dice el protagonista, "la pura aflicción”: una afectación, es decir, un ser afectado que no se transforma en empatía o en misericordia, sino en una impresión que produce una difusa inquietud o molestia.

Es en medio de estas labores que se abre otro tipo de vínculo que tiene un carácter complementario, como el 'otro lado de la moneda' marcado por la con-

12 En estas escenas el personaje Steve estaría reducido a lo que Agamben nombra como 'homo sacer'. El narrador se hace cargo de ese cuerpo por afectos que no obedecen a normas o convenciones sociales. 
tingencia: un encuentro erótico con Jill, la novia de Steve, quien llega justo cuando el narrador acaba de meter el cuerpo colapsado del anfitrión a una ducha de agua caliente:

Podría empujar a Jill hasta el cuerpo de Steve y exigir que mirara, que ella mirara sí lo que nunca había querido ver, su Steve con nada más que un cuerpo maltratado. Y que mirara pronto y bien porque un muerto es un muerto y nunca se sabe el próximo paso de su desintegración. . . Allí en la cocina, presionando con mi pubis el cuerpo de Jill contra la hornalla, allí en aquella cocina yo solo precisaba eso: una pequeña cena digna. Que Jill y yo nos quedáramos junto al cuerpo de Steve y que lloráramos abrazados. . . Había tenido una erección y sentía a Jill contra el pubis. Me pregunté desde cuándo yo estaba así. Jill volvió a pedirme que fuera rápido. Respondí que no tenía nada para hacer ni lento ni rápido. Que la única cosa para hacer era ir allí, mirar a Steve y hacernos un poco más dignos. Que no tenía otro deseo más que ese (155-6).

A diferencia de la aventura con Steve, que ocurre como consecuencia de su aceptación pasiva de los hechos y sugerencias del otro extraño, la escena erótica con Jill se despliega como la manifestación de una proximidad circunscrita a la inmediatez del momento. Sería la oportunidad para que el protagonista se deshiciera del cuidado que le exige un desconocido catatónico, la entrega a una erotización en la cual ambos participantes se ven involucrados casi como respuesta motora y refleja. Ni Jill ni el protagonista manifiestan las señas de un goce apasionado. La atracción que experimentan por el otro es el resultado del acaso de una afectación recíproca y espontánea. Ambos se entregan a la estimulación sexual en una forma similar a la que despliegan los personajes de David Cronenberg en Crash: agresivos en sus gestos, pero sin tener voluntad destructiva real. Señalábamos que la escena es complementaria en comparación al encuentro con Steve en la casi ausencia de emociones y sentimientos. Una afectación recíproca acerca los cuerpos de Jill y del narrador sin que este acercamiento sexual sea perturbado por la presencia de Steve que parece estar muriendo en la ducha al lado o por la necesidad de "mirar a Steve y hacer(se) un poco más digno" (156).

$\mathrm{Si}$ los afectos fluyen en circuitos y, a su vez, un circuito puede ser visto como una constelación de conexiones que se ponen en movimiento, entonces las escenas de Bandoleros en las que el protagonista interactúa con sujetos desconocidos nos sugieren que más allá del mecanismo predeterminado para componer el lazo social existe algo diferente: un afecto en el narrador lo empuja a "hacerse digno". En el momento de la anomia radical despierta el deseo y la oportunidad de una subjetividad 
radical de actuar con dignidad, la dignidad con la cual el narrador decide confrontar el conflicto de afectos a favor del cuerpo desprotegido de un desconocido.

Una lectura adicional que sugerimos para estos episodios se deriva de la observación que realizamos más arriba: el vínculo entre la trama y el circuito de afectos. Los dos encuentros del protagonista con Steve ocurren en momentos de desconexión entre él y su círculo social inmediato. El primero involucra la pelea con Ada, mientras que el segundo está marcado por la muerte de su amigo João y el quiebre amoroso definitivo. La forma desorganizada en que se presentan los hechos hace difícil tomar conciencia de este vínculo, como si para el propio narrador ello también fuese un hecho opaco. No afirmamos que una cosa sea la causa mecánica de la otra, esto es, que la desorganización afectiva es igual a la desorganización narrativa, sino que ambas se encuentran involucradas en la producción del desamparo.

El propio narrador no muestra ser consciente de este fenómeno, nada lo lleva a explicitar el vínculo causal entre su quiebre amoroso, la pérdida de su amigo y la entrega a la intensidad destructiva que lo orilla a Steve. Creemos que aquí se encuentra uno de los puntos centrales de la novela, pues no se trata de un ocultamiento "detectivesco" o como si el protagonista estuviese escondiendo un secreto del que se avergonzara. Por el contrario, existe en el texto una renuencia a explicitar causas lógicas o mecánicas, y ello se evidencia en el hecho de que los afectos del protagonista son asimismo afectos desamparados en tanto no son narrados bajo el tinte de la decadencia o la descomposición moral. Son afectos que el sujeto no logra significar, cuya lógica permanece oculta y que finalmente llevan al protagonista hacia un desamparo absoluto, un desamparo que siempre consiste en la confrontación con la muerte.

La emergencia de vínculos marcados por el desamparo resulta así posible bajo esta forma desorganizada y confusa, puesto que esos vínculos son, ellos mismos, desorganizados y confusos; no la teleología de lo social, sino el punto de partida para una posible nueva composición, que — siguiendo el argumento de esta narración- sería una nueva subjetividad tanto fundada en la dignidad como fundadora de ella.

\section{Estorvo y los quiebres del lenguaje}

Al igual que Bandoleros, Estorvo nos posiciona frente a una narración desprovista de la traducción de las intensidades de las afectaciones a las cuales está expuesto el narrador ya sea en emociones o sentimientos con los cuales regular sus lazos sociales. Nuevamente, el personaje principal esquiva constante y, en ocasiones, 
conscientemente, nudos o tramas emocionales densos y cuando cae en ellos el impulso parece ser apenas el azar.

A partir del recorrido que traza en su errancia el personaje principal de Estorvo - recordemos, otro personaje sin nombre-, se establece un circuito zigzagueante que va de la ciudad a la periferia (la antigua casa de campo familiar); una salida de la urbe primero como huida (huida de un visitante que toca la puerta y que el protagonista no reconoce o se niega a reconocer, similar al llamado realizado por Steve en Bandoleros), luego como un propósito fijo aunque banal: vender las joyas que ha robado a su hermana, y por último como una trampa (al ser llevado allí por un policía corrupto que está al tanto del robo). El circuito errante del personaje no supone pues un circuito afectivo coherente y que implique un lazo social entre una y otra zona. Antes bien, cada encuentro o cruce interpersonal del recorrido infiere una parada y no un punto de llegada en la que sucede un quiebre y un cortocircuito de los afectos, donde los afectos "estorban" y lo que se abre es un vacío o distancia mayor entre los personajes. Cortocircuitos que descomponen las máscaras de las diversas subjetividades ofrecidas por el proceso de socialización que ha recorrido el personaje (hijo, hermano, esposo, ciudadano responsable) y lo llevan al final a una situación de desamparo radical. El lector asiste pues a esta disolución de las formas de subjetividad coercitiva y socialmente impuesta.

El lazo social, incluso al interior de unidades afectivas que se suponen densas como la familiar, se reduce a relaciones emocionales mínimas vaciadas de lenguaje y performatividad. No existe una comunicación efectiva entre el protagonista y su hermana (a quien el narrador se acerca afectivamente solo en sus recuerdos de infancia y en un deseo con tintes incestuosos en el presente de la narración). De hecho, la única demostración de cercanía emocional en esta configuración se revela en la ayuda financiera que el narrador recibe de su hermana, reduciendo el vínculo a una transacción monetaria. Asimismo, el contacto que se intenta establecer con la madre por medio de llamadas telefónicas es siempre un contacto truncado por la imposibilidad del habla: el protagonista telefonea y la madre se queda callada al otro lado de la bocina o este decide colgar el teléfono un segundo antes de que su madre conteste. El narrador también recuerda el proceso que llevó a la total disolución del lenguaje afectuoso con su ex esposa, un lenguaje en el cual las emociones se correspondían con las afectaciones: el paso de la hipérbole emocional "te amo mais que tudo", enunciado por la mujer mientras estaban juntos, a las transacciones verbales mínimas marcadas por un lenguaje que incluso prescinde de la gestualidad implícita. Estando ya separados, ella se comunica frente a frente con él "praticamente sem mover os lábios" (39). 
Así, a diferencia de Bandoleros, donde el vínculo se establece con extraños a partir de afectos desamparados sin la posibilidad de transformarse en emociones, en Estorvo asistimos a un juego de afectos que corroen los registros emocionales y al extrañamiento de las emociones tradicionales. La tríada que constituye la típica red afectiva masculina: madre, hermana y pareja, opera menos como soporte del individuo que como afirmación de la dilución del yo y de sus estructuras emocionales. Sin embargo, en ambos casos podemos identificar vínculos por desposesión: aquellos que provocados por afectos desamparados, afectos que no consiguen ser significados emocionalmente por una subjetividad intacta y consistente se establecen con un otro cualquiera, y los que se crean de la incapacidad de traducir los afectos familiares y de pareja en lazos emocionales; el primero por proximidad y el segundo por distanciamiento, este último evidenciado y reforzado en las rupturas del lenguaje.

Este fracaso de la comunicación revela otra declinación del desamparo en la que los afectos no encuentran su amparo o lugar en el lenguaje demostrando cómo el circuito de afectos tradicional ya no contribuye a configuraciones emocionales aptas para crear vínculos sociales, sea de reconocimiento y conciliación o de conflicto (odio, rabia, desdén). A este respecto, uno de los momentos clave ocurre en la llegada del narrador al "sitio" familiar, un lugar en la montaña a una "hora e quinze de curvas e aclives" de Rio. Tras cinco años de ausencia, el protagonista se reencuentra con el mayordomo del lugar tropezando con las coordenadas que tradicionalmente guiaban los rituales y los modos de comportamiento de este tipo de encuentros. Piensa en saludarlo y darle un golpe suave en la espalda, pero esa "intimidade soaria falsa". Si fuera su padre, "entraría soltando uma gargalhada na cara do velho, passaria a mão naquele cabelo gorduroso, talvez chutasse o tamborete e dissesse "levanta daí, sacana" (26). Su padre habría actuado como un fiel representante de los hombres "cordiales" que a través de la familiaridad del contacto y de la indistinción de fronteras entre lo público y lo privado trataba a todos de forma íntima para mejor establecer su propia autoridad y jerarquía. ${ }^{13}$ En contraste, el narrador no tiene palabras ni gestos, solo puede decir "há quantos anos, meu tio", una expresión que incluso suena ofensiva a oídos del mayordomo, pues como bien señala el narrador: "é outro idioma” (26). En este quiebre y economía del len-

13 El "hombre cordial" es uno de los más decisivos y debatidos aportes que el historiador Sérgio Buarque de Holanda (el padre de Chico Buarque), realizó al pensamiento brasileño en su libro Raíces del Brasil. El hombre cordial definía, según el autor, uno de los tipos ideales brasileños donde lo cordial no se refería a un sustrato afectivo sino a la constante imbricación de lo privado en lo público, a la primacía de lo doméstico sobre lo político, donde la proximidad de las relaciones encubría relaciones asimétricas de poder. 
guaje es posible identificar la incapacidad de convertir la afectación producida por el reencuentro con el espacio familiar y con el mayordomo en gestos emocionales. La situación solo produce en el narrador afectos desamparados que no disponen de una gramática de emociones o de sentimientos por medio de la cual establecer una comunicación con el mayordomo.

Aquel típico hombre cordial representado en la figura del padre no solo se respaldaba en un lenguaje asimismo "cordial" sino también en una gestualidad en la cual lo afectivo encuentra su expresión emocional. Esta performatividad de las emociones resulta nuevamente trastocada y parece apenas supeditada al espectáculo de la marginalidad - tal como se revela en la entrevista que realizan a la madre de un supuesto asesino que llora ante las cámaras y suprime el llanto cuando las cámaras dejan de grabarla—; o al pasado —en el momento del reencuentro entre el narrador y el mayordomo, quien primero lo confunde con un familiar y bajo esta condición lo abraza y luego, al percatarse de quién es realmente, llora, como alguien (como el padre) en quien las afectaciones todavía producían sentimientos. Sin embargo, en el primer caso se trata de una performatividad que más que demostrar la veracidad o calidad de las emociones da cuenta de su artificialidad: el llanto es solo para los medios. En el segundo caso, el mayordomo percibe de inmediato que su reacción emocional no era apropiada ni se correspondía con los sentimientos hacia el hijo de su antiguo patrón: de hecho, cuando el narrador necesita su ayuda frente a la amenaza de los narcotraficantes que se apropiaron del campo familiar, el mayordomo simplemente desaparece evitando ser afectado por un mundo que no tiene nada que ver con el suyo.

El dislocamiento radical entre los afectos y las emociones y su lenguaje performativo se comprueba de manera fehaciente hacia el final de la novela cuando el narrador, en su última huida del campo de la familia, va hacia la parada del bus y encuentra allí a un hombre que cree reconocer. Quizá sea este el único momento en el que el protagonista anuncia sentirse embargado por un "sentimiento" al ver al hombre allí parado:

...não sei por que, encheme de um sentimento semelhante a uma gratidão". Sentimiento que desencadena una performatividad afectiva y un desenlace que podría ser, o no, fatal: "Sigo correndo ao seu encontro, de braços abertos, mas ele me interpreta mal; encolhe os ombros e puxa uma faca de dentro da calça. . . Recebo a lâmina inteira na minha carne, e quase peço ao sujeito para deixá-la onde está. . . (140). 
La gramática afectiva común, la de la violencia generalizada, termina por determinar a todos como sujetos 'a' y sujetos 'de' la violencia (la sujeción). Percibir al otro en su subjetividad como resultado de una vida concreta, y entrar en un acto comunicativo que parta y confirme la subjetivación, parece pues imposible. El lenguaje y las acciones afectivas comunes y la circulación de afectos signados por la violencia no permite percibir el desamparo del otro. La interpretación del evento se traducirá así en cadenas de equívocos que confirman la violencia generalizada. Y la herida, como marca corporal y final del desamparo, suspende su significación y queda abierta. ¿Quién terminará siendo afectado por ella, un transeúnte casual, un funcionario de un puesto de auxilio, un familiar del protagonista herido, o acaso este muere sin ninguna asistencia? El lector no puede saberlo. El resultado más probable, no obstante, es que la herida sea interpretada por la gramática general de los afectos como resultado de un acto de violencia cualquiera, y no como el signo de un desamparo radical.

\section{Longe da água y la descomposición de los círculos afectivos sociales}

El momento decisivo de la novela Longe da água de Michel Laub es la muerte de Jaime, amigo del narrador. Jaime se ahoga frente a sus ojos sin que este tenga la posibilidad de salvarlo. Ese es, por lo menos, el relato del narrador al inicio de la novela del accidente de surf sufrido por su amigo admirado y modelo inalcanzable: un chico popular en el colegio que debe su éxito con las mujeres gracias a su cuerpo atlético y a su habilidad como surfista.

Las visitas de los compañeros al solitario y desesperado padre del amigo muerto ofrecen al narrador la oportunidad de conocer mejor a Laura, la chica que había sido una aventura de verano de Jaime, a quien finalmente el protagonista se atreve a besar. Una historia que en apariencia no tiene consecuencias. Años más tarde, terminada su formación en letras y siendo colaborador en una editorial, el narrador se reencuentra con Laura de forma casual. Surge un interés recíproco que se convierte en un enamoramiento y deciden vivir juntos. Una vida marcada por la normalidad, por los conflictos y reconciliaciones de la cotidianidad que termina de manera abrupta con el accidente automovilístico — donde no tiene ninguna responsabilidad el narrador- en el cual muere Laura.

Vemos cómo en las tres novelas se repite una historia parecida: casualidades, eventos sin transcendencia, encuentros con personajes desconocidos en las primeras dos novelas y una vida sin acontecimientos extraordinarios en la última, llevan a los narradores-protagonistas a una situación límite, a una situación de desamparo radical que, en cada una de las novelas, implica al mismo tiempo la confrontación 
con la muerte. No obstante, el desamparo es el momento en el cual el sujeto se libera de cualquier sujeción y recupera la libertad de convertirse en sujeto, aunque debe transitar por la experiencia de la precariedad radical de su vida.

La crisis psíquica que el narrador sufre hacia el final de la novela y su cuarentena en una clínica psiquiátrica es provocada por el derrumbe de la economía de afectos y por el colapso de la administración de los mismos, cuyo objetivo es la formación de una subjetividad socialmente reconocida. El accidente, la muerte de Laura, y el autoconocimiento que alcanza en su tiempo de cuarentena lo hacen consciente de que toda su vida, su éxito profesional, y particularmente la conquista de Laura — desde el primer beso hasta la vida en común-, serían apenas un artificio para ocupar el lugar de su admirado amigo a quien, además, había traicionado en el momento de su muerte. Debido a los recuerdos que surgen en la clínica psiquiátrica, el narrador revela que habría sido posible salvar a Jaime, que la distancia no era insuperable y que las corrientes no eran demasiado peligrosas. Convertido en un buen nadador gracias al esfuerzo por seguir el modelo de su amigo, rescatar a Jaime no era imposible. Habría sido el miedo a que el amigo se sujetara a él y el temor a ahogarse juntos la causa de su parálisis. La vida del narrador se habría así construido con el propósito de olvidar la última mirada de Jaime: una mirada que no sabemos si era de desesperación — porque el amigo no acudía a su salvación-, o una mirada de desprecio, que confirmaba la cobardía de aquel que no habría tenido el valor de arriesgar su propia vida.

La afectación del narrador ante la última mirada de Jaime en su lucha contra la muerte cuestiona radicalmente todos sus esfuerzos por cumplir con su propia imagen de sujeto. Al final de la novela, a partir de la muerte de Laura, se dará cuenta de que la estrategia de su vida habría sido apenas construir una subjetividad que hiciera desaparecer y reprimir la afectación de esa mirada: su primer beso con Laura, su exitosa vida profesional, su reencuentro con Laura y la decisión de vivir con ella una vida normal de intelectuales profesionales. El choque producido por la muerte de la esposa y los recuerdos de su propio actuar al momento de la muerte de Jaime lo llevan al desamparo radical y a la descomposición de una economía afectiva precaria. Entregarse al desamparo y admitirlo como experiencia es consecuencia del derrumbe (o del rechazo) de la subjetivación ofrecida y exigida por las instituciones culturales, sociales y políticas y las convenciones y costumbres que determinan la subjetivación.

¿Dónde, pues, y cómo, detectamos en estas novelas manifestaciones de una subjetividad que resulta de las afectaciones a las cuales el individuo se expone en su singularidad y no actúa de acuerdo a su sujeción a una ley, un orden, reglamen- 
tos, convenciones o costumbres? Sería en los momentos en los cuales se deshacen todos los lazos sociales: los institucionales, los familiares y los lazos de amistad. En suma, momentos marcados por la soledad radical que sobreviene tras la aceptación de la inautenticidad de las relaciones y los afectos que las constituían con la consecuente imposibilidad de reconocerse en esas mismas redes y afectos. Esto se cumple en la trayectoria de los narradores de las tres novelas aquí presentadas. Y la manifestación y expresión de una subjetividad en vías de recuperación, o mejor, de refundación, es su propio acto de narrar, de contarse a sí mismo. Es el narrar como acto de habla, no para sobrevivir como en el caso de Sheherezade (que en ningún momento habla de sí misma, condición de su sobrevivencia), sino para ordenar los elementos de un pasado de manera que se abren fisuras, discontinuidades y contradicciones. El narrador de Longe da água tiene que romper con todas las auto-interpretaciones y ofertas convencionales (en las relaciones con amigos, en su mundo profesional y finalmente en su convivencia con Laura), tiene que forzar esta circulación de afectos bien arreglada (un acto al cual es arrojado por el accidente con Laura y su muerte) que reprimió a la afectación existencial surgida de la última mirada de su amigo Jaime. La refundación de la subjetividad la detectamos, repetimos, en el narrar. Es por este motivo que el estilo de las narraciones recuerda en muchos pasajes a la "poesía en prosa" reivindicada por Baudelaire en "El spleen de París". De hecho, la experiencia del spleen tiene bastantes similitudes con los afectos desamparados de nuestras novelas.

En la poetización de lo subjetivo por medio del lenguaje, de sus estructuras gramaticales, en el ritmo del lenguaje, en la constelación de motivos e imágenes y en la densidad o la desenvoltura de las formulaciones es donde reside la objetividad más rigurosa que la literatura puede ofrecer a la subjetividad más radical y su singularidad. Los afectos desamparados que llevan en nuestras tres novelas a sus narradores al desamparo y, con ello, a una abertura radical que transgrede las realidades que buscan disciplinar y controlar los afectos, encuentran su respaldo y su legitimación en el propio lenguaje, en la justicia del lenguaje (Sprachgerecbtigkeit). Su justicia (Dike), como nos enseña Hamacher, renuncia a tomar decisiones excluyentes, se libera de actos predicativos y acoge todo lo que se refugia en ella.

\section{Conclusiones}

El horizonte marcado por una subjetividad ideal ha sido, sin lugar a duda, una fuente rica y generosa en el delineamiento por contraposición de los personajes que pueblan la literatura moderna plagada de subjetividades problemáticas, contradictorias y a veces, también, desamparadas: locos, revolucionarios, melancólicos y 
delincuentes son apenas una muestra de la constante confrontación con las duras exigencias del ideal y de la imposible construcción del yo pleno de la modernidad. ${ }^{14}$

Ahora bien, como intentamos mostrar, la crisis de la subjetividad de los protagonistas de nuestras novelas tiene otra razón: se trata de una crisis de la propia subjetividad en la cual no es posible ni siquiera imaginar o desear una subjetividad alternativa, y no es por la distancia que los separa del ideal sino por el agotamiento mismo de los límites y alcances de los modelos de subjetividad tradicionales y por el develamiento de que la subjetividad, así como el poder, parece instalarse en un vacío (Safatle). En este sentido, el tránsito y sumergimiento de los protagonistas en el desamparo sería menos un rasgo nihilista de los personajes que un necesario desmonte de la subjetividad como sujeción, cuyos pilares se revelan agotados y deficientes, quizá por su abierta y arrogante pretensión de consistencia y coherencia. Una coherencia y consistencia ganadas por los sujetos a cambio de su singularidad inestable, a veces herida y siempre frágil.

Las fases que debe atravesar la descomposición de la subjetividad se esclarecen y comparten rasgos comunes en las tres novelas, tanto en el choque frente a las expectativas en el ámbito íntimo y privado como frente a las expectativas públicas. En primer lugar, ninguna aspiración tradicional asociada al mundo de las relaciones marcadas por sentimientos románticos se realiza, menos aún las relaciones familiares e incluso no llegan a cumplirse, o se ven truncadas por la desaparición y la muerte, las relaciones de amistad. Esta última dimensión de circuitos afectivos signados por la afectación de un ser singularizado y su necesidad y deseo de una nueva comunidad estaría, al parecer, libre de imposición. Sin embargo, solo aparece como un reducto de instauración o restauración de la singularidad en Bandoleros, donde João, el amigo incondicional, muere a causa de una enfermedad, y en Estor$v o$, en el recuerdo de la antigua amistad perdida con un joven y también singular poeta. En Longe da água, por el contrario, son justamente las deficiencias y faltas que acusa el protagonista, quien no habría sabido responder y actuar como un "verdadero" amigo, las desencadenantes del proceso de descomposición subjetivo.

Frente a las expectativas públicas la entrega y potencia del desamparo se revela en una figuración performativa clave: la disolución de los circuitos de afectos que sostenían precariamente a las subjetividades diluye a su paso el miedo, el miedo a la norma y a la ley, sin que esto signifique que nuestros protagonistas se tornen héroes valerosos o que su enfrentamiento a la norma responda a una acción consciente y decidida. Se trata, simplemente, de sujetos que no tienen nada que perder, pues perdieron lo último que tenían: la posesión de sí mismos y sus antiguos

14 En Freud el Ich-Ideal ("Das Ich und das Es"). 
predicados (Safatle). Sin respuesta alguna a los dispositivos securitarios que se han instalado contra el miedo, las violencias procesuales del desamparo emergen entonces con fuerza bajo diversas manifestaciones performativas, sin que esto se traduzca en agresividad manifiesta o resuelta o, mejor dicho, en la conversión de sujetos seguros en y de su violencia. Antes bien, como ocurre al final de Estorvo, se llega al punto de abrazar casi amorosamente la violencia del otro (140).

Ahora, para que estas subjetividades corroídas y en proceso de descomposición superen la mera crítica al ideal tradicional de la subjetividad moderna, más que una confrontación con los ideales sería necesaria una renuncia que prefigura un retorno a un punto cero, el punto cero del desamparo que no es el punto de la pureza ni de la singularidad intocada (no sería el recién nacido desamparado de Freud), sino un punto cero como una aceptación de la singularidad que desemboca en el desamparo con las heridas dejadas por la sujeción, que reconoce su fragilidad y las marcas de la violencia de la propia dinámica procesual del desamparo en su lucha por el desprendimiento, singularidades semejantes a las figuras humanas deformadas de horror y violencia de Francis Bacon.

Así, en la habitación del limbo en la que desembocan estas subjetividades desmontadas, que por momentos oscilan entre la seducción del gozo del propio sufrimiento y la exposición de este en su forma de desamparo, reside la única posibilidad de un desvío radical que no solo alcance y trascienda a la singularidad propia sino que tenga como horizonte la instauración de nuevos sentidos de lo común. ¿Puede entonces crearse a partir de esta destitución un nuevo cuerpo político? Las narraciones revelan, al menos, que no podrá restituirse la normalidad del sujeto que se era antes de la crisis, lo que prefigura una nueva forma de sí. El desamparo se muestra pues aquí, como señala Safatle, en su punto más pleno de ambivalencia, como mera potencia transformadora. El punto a partir del cual un antiguo régimen de circulación de afectos entra en declive o es puesto en cuestión y un nuevo modo de afectación y, quizá, de incorporación de lo común, asoma.

Si bien el poder de la literatura para la necesaria reconfiguración de los circuitos afectivos que reclama nuestro tiempo probablemente parece muy débil, las novelas exponen trayectorias de experiencia donde el desamparo es un camino procesual posible y ahonda en el trabajo de crítica necesario para repensar otros modelos de subjetividad. Tal como señala Safatle, si la sujeción se construye y perpetúa afectivamente, la única vía para superarla es a través de sus propios medios, es decir, a partir de un nuevo régimen de afectividad producido por otro régimen de aiesthesis (38). 


\section{Obras citadas}

Abramowski, Ana y Santiago Canevaro. "Introducción". En Pensar los afectos, aproximaciones desde las ciencias sociales y las humanidades. Buenos Aires: Ediciones UNGS, 2017: 9-26.

Ahmed, Sara. La politica cultural de las emociones. México D.F.: Universidad Nacional Autónoma de México, 2015.

Berlant, L. "Cruel Optimism". En Gregg, Melisa; Seighworth, Gregory (eds.). The affect theory reader. Durham: Duke University Press, 2010: 93-117.

Buarque, Chico. Estorvo. São Paulo: Companhia das Letras, 1991.

Buarque de Holanda, Sérgio. Raíces del Brasil. Buenos Aires: Ediciones Corregidor, 2016.

Butler, Judith. Los mecanismos psíquicos del poder: teorías de la sujeción. Madrid: Ediciones Cátedra, 2001.

Flatley, Jonathan. Affective Mapping. Melancholia and the Politics of Modernism. Cambridge, London: Harvard University Press, 2008.

Freud, Sigmund. "Conferencia 31. La descomposición de la personalidad psíquica". Nuevas Conferencias de Introducción al psicoanálisis. Obras completas. Volumen XXII. Buenos Aires: Amorrortu editores, 1991: 53-73.

--- "Das Ich und das Es". En Gesammelte Werke, tomo XIII. Frankfurt: S. Fischer Verlag, 1999: 237-289.

---. "Das Unbewusste". En Gesammelte Werke, tomo X, Frankfurt: S. Fischer Verlag, 1999: 263-303.

--- "La angustia". Lecciones introductorias al psicoanálisis. Obras completas. Volumen XVI. Buenos Aires: Amorrortu Editores, 1991: 357-373.

Hamacher, Werner. "Dike - Sprachgerechtigkeit". En Hamacher, Werner. Sprachgerechtigkeit. Frankfurt: S. Fischer Verlag, 2018: 7-49.

Lara, Ali y Domínguez Giazú Enciso. "El giro afectivo". Athenea Digital 13, 3 (2013): 101-119

Laub, Michel. Longe da agua. São Paulo: Companhia das Letras, 2004. 
López González de Orduña, Helena. "Prólogo. El giro emocional”. En Sara Ahmed. La politica cultural de las emociones. México D.F.: Universidad Nacional Autónoma de México, 2015: 9-16.

Massumi, Brian. The Politics of Everyday Fear. Minneapolis, London: University of Minnesota Press, 1993.

Marx, Karl - Friedrich Engels - Werke, Band 23, "Das Kapital". Bd. I, Erster Abschnitt, S. 49 - 98, Dietz Verlag: Berlin/DDR, 1968.

Ngai, Sianne. Ugly feelings. Cambridge, London: Harvard University Press, 2005.

Noll, João Gilberto, Bandoleros. Buenos Aires: Adriana Hidalgo Editores, 2007.

Riha, Rado. "Das transzendentale Subjekt und sein Dawider". Filozofski vestnik, XXXVI, 2 (2015): 139-154.

Safatle, Vladimir. El circuito de los afectos. Cuerpos políticos, desamparo y el fin del individuo. Cali: Editorial Bonaventuriana, 2019.

Shouse, Eric. "Feeling, Emotion, Affect". M/C Journal 8, 6 (2005). [http://journal. media-culture.org.au/0512/03-shouse.php] Consultado el 02/02/2020.

Sussekind, Flora. "Desterritorialização e forma literária. Literatura brasileira contemporânea, a experiência urbana.” Literatura e sociedade 8 (2005): 60-81.

Widmer, Peter. "Affekt und Fantasma”. En: Riss. Zeitschrift für Psychoanalyse. FreudLacan. Baden, 2015: 41-57. 